\title{
EN HONOR A LOS 40 AÑOS DE ANIVERSARIO DE LA REVISTA MÉDICO CIENTÍFICA
}

\author{
POR: PAVE MISLOV VALLARINO
}

EDITOR EN JEFE

El 2020 fue un año que cambió el curso de la historia de la humanidad; los besos y los abrazos fueron cambiados por mascarillas y protectores faciales. Nunca antes mantener la distancia había sido considerado como uno de los gestos de aprecio más grandes. Entre tanta conmoción e incertidumbre, sale a relucir la importancia de la evidencia por encima del empirismo; lo objetivo sobre lo subjetivo. Durante 40 años, los estudiantes de la Facultad de Medicina de la Universidad de Panamá han llevado adelante una fuente de la verdad actualizada, objetiva y sustentada con estudios y evidencias para brindar a todos sus lectores un poco de la tan anhelada certeza sobre distintos temas del campo biomédico; la Revista Médico Científica (RMC).

En 40 años de existencia, la RMC ha pasado por momentos históricos adaptándose a la época y superando grandes obstáculos. Entre estos, una dictadura, una invasión y hasta una pandemia donde no solo se ha mantenido, sino que ha crecido. Esto ha sido logrado gracias a la dedicación y cariño de todos los que alguna vez pertenecieron a la RMC. Este breve escrito tiene como objetivo agradecer a todos y cada uno de los miembros que alguna vez dedicaron su tiempo para esta noble causa. Además de ello, destacar la labor de quienes han tenido la oportunidad de dirigir esta gran iniciativa por mantener informada a la población médica, en especial a los que son el futuro de la salud en nuestro país y el mundo, los estudiantes de medicina.

Quien ha realizado un escrito científico conoce lo complejo y arduo que es la producción de literatura científica. La revisión de la misma tampoco es un proceso fácil ni corto. El producto final del trabajo entre autores, pares y editores es lo que permite la formación de nuevo conocimiento y brinda un norte en momentos donde la humanidad se encuentra atrapada en un mar de incertidumbre y desinformación. Por 40 años la RMC ha sido parte de esta y además ha aportado a la formación de grandes médicos que hoy día son referencia internacional en su campo.

La RMC nace en 1980 con la iniciativa del grupo bajo la dirección del Dr. Jorge Vanegas y continúa en sus primeros 10 años bajo la dirección de doctores como el Dr. Juan Miguel Pascale, el Dr. Enrique García, la Dra. Marta Illueca, el Dr. Tomás P. Owens y el Dr. Norberto Calzada. Fue bajo la dirección de estos doctores que se sentaron las bases para la generación y publicación del conocimiento en la Facultad de Medicina de la Universidad de Panamá. Hoy día las bases que nos dejaron han permitido el crecimiento de la RMC hasta el punto de ser referencia para el inicio de otras revistas a nivel nacional. Agradecemos profundamente que, tras años de haber sido parte de los inicios de la revista, hoy día nos asistan como pares expertos en sus respectivos campos, dando así continuidad y crecimiento a lo que en entonces construyeron.

Entre el 20 de diciembre de 1989 y el 31 de enero de 1990, Panamá sufre uno de los eventos más difíciles de su historia, la Operación “Causa Justa” que consistió en la invasión de los Estados Unidos, trayendo consigo grandes En honor a los 40 años de aniversario de la Revista Médico Científica by Mislov Vallarino, Pave is licensed under a Creative Commons Attribution-NonCommercial-NoDerivs 4.0 Unported License. 
cambios en la realidad panameña. Correspondió, en 1990 al Dr. Ralph Hauke dirigir la RMC y gracias al continuo esfuerzo de doctores como la Dra. Maria Abbott, el Dr. Rafael Perez Castillo, el Dr. Victor Urrutia, la Dra. Susana De León, la Dra. Yamileth Hernandez, el Dr. Fotis Takis, el Dr. Alcibiades Rodriguez, el Dr. Jorge Calzada, la Dra. Ana Vincensini, el Dr. Frederman Concepción y la Dra. Geraldine Norte, la RMC supera una década de retos y llega a sus 20 años buscando adaptarse a lo que traería el nuevo milenio. Hay que destacar que hasta este punto todo lo concerniente a la revista se había trabajado en las bibliotecas, ya que el internet y el acceso abierto al conocimiento del mundo en la palma de la mano era todavía un sueño. Además de esto la forma para difundirla era únicamente la versión impresa, lo que en una época tan difícil representaba gastos tanto en papel como en tinta para que el producto fuese de calidad desde su contenido hasta su presentación. La calidad de este trabajo era tal, que algunas copias de ejemplares impresos aún se encuentran en excelente estado en el baúl de los recuerdos de la RMC.

El siglo XXI trae grandes cambios. Entre estos, el inicio de la publicación digital de la RMC. Los siguientes doctores lideraron durante la tercera década de la revista el proceso de adaptación a la era de la información: el Dr. Noel De Obaldía, la Dra. Ana Belén Araúz, la Dra. Nahir Ubillús Bonini, el Dr. Cesar Pérez Batista, el Dr. Jan Cubilla, la Dra. Ariane Abrego, la Dra. Lilliana Tang, la Dra. Yeniffer Nicholas, el Dr. Roberto Ferro, la Dra. Emmy Arrue, la Dra. Clarissa Botello, el Dr. Melchor Rivera, el Dr. Eucaris González, la Dra. Larissa Calvo y la Dra. Ana Cooke. Es en esta década donde las tecnologías provocan una explosión en la difusión del conocimiento. La RMC evoluciona, dejando atrás el papel, pero expandiendo sus horizontes al alcance de todo el mundo gracias al internet. A pesar de las nuevas facilidades, la producción, revisión y edición de ciencia para publicar continúa siendo una ardua tarea que a cada paso que progresa, exige estándares de calidad cada vez más altos. Estándares que cada generación de nuevos editores ha trabajado para mantener y superar.

La cuarta década de la RMC ha enfrentado grandes retos. La difusión del conocimiento permanece en continua evolución obligando a actualizar tanto el conocimiento que se produce como la forma de difundirlo. Corresponde a los siguientes doctores liderar dicho progreso: Dra. Amarilis Maltéz, Dr. Musharaf Tarajia, Dr. Antonio Alvarado, Dr. Luis Andros, Dra. Melissa Bonilla, Dra Ana Gabriela Bernal, Dra. Amarilis Salado, Dr. Jhonattan Camaño, Dr. Edwin Araúz, Dr. Harold Bravo y Dr. Ruben Mariscal. Fueron los aportes que cada uno de los miembros del equipo de trabajo con que contaron los doctores que he mencionado los responsables de tener hoy una revista científica ejemplar que cuenta con su propio dominio, servidores actualizados, nuevas indizaciones, pero sobre todo con un equipo de trabajo organizado que internamente se capacita de los miembros más antiguos a los más nuevos.

La RMC concluye su cuarta década enfrentándose a un reto sin precedentes. La pandemia de COVID-19 ha causado que los aviones aterricen, que la gente se encierre, y que la economía desacelere. Sin embargo, reluce la importancia de la decisión médica basada en la evidencia. Quienes ya no viajan, leen; quienes están en casa, investigan; y las inversiones en ciencia salud y tecnología para salvar, aumentan. La producción de ciencia durante este momento ha sido explosiva y desde el comienzo, la Revista Médico Científica, su equipo de trabajo y los estudiantes de medicina de la Facultad de Medicina de la Universidad de Panamá hemos transformado los retos en oportunidades para aprender, investigar, publicar y sobre todo enseñar. Celebramos los 40 años de la Revista Médico Científica desde casa, difundiendo conocimiento basado en evidencia, sembrando en cada estudiante que podamos la semilla de la investigación, enseñando la lectura crítica de literatura científica a cada persona que esté a nuestro alcance, que hoy más que nunca es de vital importancia. 
Para la redacción de este breve escrito dedicado a los 40 años de la RMC, solicitamos reseñas a la mayor cantidad posible de editores en jefe pasados sobre su valiosa experiencia y legado de haber dirigido la RMC. Como editor en jefe del año 2020, puedo dar fe que desde 1980 hasta el 2020, el equipo de trabajo ha sido siempre la fuente de vida de la RMC. Las lecciones aprendidas y la huella que deja la RMC en cada miembro es en esencia la misma. Mejora de las capacidades para el trabajo en equipo, la pasión la investigación, el desarrollo de la lectura crítica y en ocasiones ha sido fundamental para la decisión del curso de vida de algunos miembros.

Quisiera concluir motivando a todos los actuales y futuros miembros a seguir con el gran cariño y trabajo que por 40 años se ha realizado en la RMC. El tiempo que se le dedica es una inversión para su futuro y el aprendizaje que se obtiene es para toda la vida. Nunca antes había sido tan importante generar evidencia y evaluar la calidad de la evidencia como lo es hoy y siempre recordar que la ciencia que no se publica, no existe.



Pave Mislov Vallarino

Editor en Jefe 2020-2021 